\section{Década da Ação em Nutrição e tributação de bebidas açucaradas no Brasil: onde estamos?}

\author{
Decade of Action on Nutrition and sugary drinks \\ taxation in Brazil: where are we?
}

Década de la Acción en Nutrición y tributación de bebidas azucaradas en Brasil: ¿dónde estamos?
Aline Brandão Mariath 1,2

Ana Paula Bortoletto Martins 3

\section{Resumo}

O Brasil foi o primeiro país a comprometer-se com a Década da Ação em Nutrição da Organização das Nações Unidas, com metas ambiciosas relativas ao controle da obesidade e à redução do consumo de bebidas açucaradas. Neste estudo, descrevemos as iniciativas legislativas relacionadas à tributação de bebidas açucaradas apresentadas no Congresso Nacional durante os primeiros quatro anos da Década e a situação do processo decisório. Foram buscadas, nas bases de dados da Câmara dos Deputados e do Senado Federal, todas as propostas apresentadas entre 2016 e 2019 que tratassem do tema, sendo apresentados os resultados de forma narrativa, descrevendo-se o conteúdo dos projetos e a situação da tramitação. Ao todo, foram identificadas dez propostas. Seis delas visam ao aumento da tributação e ainda se encontram em apreciação de Comissões na Câmara dos Deputados. Quatro propostas buscavam sustar um ato normativo que resultou no aumento da tributação sobre concentrados de refrigerantes e foram rejeitadas e arquivadas. Ainda há um longo caminho a ser percorrido para o aumento da tributação das bebidas açucaradas no país. A complexidade e a morosidade do processo decisório no Congresso Nacional impõem dois riscos: que nenhum projeto seja convertido em lei ou, caso o seja, que não cause qualquer impacto na saúde pública até 2025.

Obesidade; Bebidas Gaseificadas; Açúcares; Impostos; Política Pública

\author{
Correspondência \\ A. B. Mariath \\ Departamento Médico, Câmara dos Deputados. \\ Praça dos Três Poderes - Anexo III da Câmara dos Deputados - \\ Subsolo Ala B, Esplanada dos Ministérios, Brasília, DF \\ 70160-900, Brasil. \\ alinemariath@gmail.com \\ 1 Departamento Médico, Câmara dos Deputados, Brasília, \\ Brasil. \\ 2 Programa de Pós-graduação em Nutrição em Saúde Pública, \\ Universidade de São Paulo, São Paulo, Brasil. \\ 3 Núcleo de Pesquisas Epidemiológicas em Nutrição e Saúde \\ Pública, Universidade de São Paulo, São Paulo, Brasil.
}




\section{Introdução}

A obesidade e as doenças crônicas não transmissíveis associadas à má alimentação estão entre os maiores problemas de saúde pública enfrentados mundialmente. No Brasil, o cenário não é diferente: há pouco mais de uma década, segundo dados da Pesquisa de Orçamentos Familiares (POF) de 2008-2009, a obesidade acometia 14,3\% das crianças, 4,9\% dos adolescentes e 14,8\% dos adultos 1 . Diante disso, o país foi o primeiro a comprometer-se formalmente com a Década da Ação em Nutrição (2016-2025) da Organização das Nações Unidas, em 2017. Na época, estabeleceram-se metas bastante ambiciosas, como impedir o avanço da obesidade na população adulta e reduzir em, pelo menos, 30\% o consumo de bebidas açucaradas entre os adultos até o ano de 20192.

Frente à relação entre o consumo excessivo de açúcar e a ocorrência de obesidade e diabetes e considerando que as bebidas açucaradas são uma das principais fontes de açúcar na dieta de indivíduos e populações, a Organização Mundial da Saúde (OMS) e a Organização Pan-Americana da Saúde (OPAS) têm reiteradamente defendido o aumento da sua tributação como importante medida regulatória a ser adotada pelos governos 3,4,5.

De fato, o aumento de preço das bebidas açucaradas tem se mostrado efetivo para a redução da compra desses produtos, tanto em estudos experimentais 6,7,8 quanto em análises de impacto realizadas em países que já adotaram essa recomendação 9,10,11. Apesar de os reais efeitos sobre a saúde em nível populacional ainda não estarem claros, é preciso ter em mente que se trata de uma intervenção apenas recentemente adotada.

No Brasil, é atribuição do Congresso Nacional dispor sobre todas as matérias de competência da União, incluindo as que regem o sistema tributário, a arrecadação e a distribuição de rendas. Assim, eventuais medidas regulatórias que aumentem a tributação de bebidas açucaradas devem se dar, prioritariamente, por meio de Lei Federal Ordinária, sancionada pela Presidência da República após aprovação em ambas as Casas Legislativas (Câmara dos Deputados e Senado Federal) 12.

Neste estudo, descrevemos as iniciativas legislativas relacionadas à tributação de bebidas açucaradas apresentadas no Congresso Nacional brasileiro durante os primeiros quatro anos da Década da Ação em Nutrição e a situação atual do processo decisório.

\section{Métodos}

Foram examinadas todas as propostas legislativas apresentadas no Congresso Nacional no período entre 2016 e 2019 que tratassem, em alguma medida, da tributação de bebidas açucaradas. As propostas de interesse para este estudo foram selecionadas a partir daquelas identificadas para uma análise relativa à regulação das práticas da indústria de produtos ultraprocessados que tramitaram nesse mesmo período. Na ocasião, optou-se por empregar uma estratégia de busca ampliada, utilizando-se palavraschave que incluíam, entre outras, aquelas relacionadas às bebidas açucaradas (refrigerantes, bebidas açucaradas, açúcar) e limitando-se às matérias que tramitaram de 2016 a dezembro de 201913.

Uma vez que o Poder Legislativo no Brasil adota o regime bicameral, os projetos foram identificados a partir de pesquisas nas bases de dados internas das Casas Legislativas. Na Câmara dos Deputados, a busca foi realizada no Sistema de Informações Legislativas (Sileg), em sua versão acessível para servidores da Casa, por uma das autoras do artigo. No Senado Federal, a busca foi realizada pelo Serviço de Pesquisa Legislativa (Sepel), a partir de solicitação em que foram fornecidos as palavraschave e o período de interesse.

Procedeu-se à leitura das ementas dos projetos encontrados, e aqueles que potencialmente pudessem tratar do tema de interesse foram lidos, na íntegra, por uma das autoras do artigo para a decisão quanto à sua inclusão. Eventuais dúvidas quanto à inclusão ou não foram decididas por consenso entre as duas autoras. Definidas as proposições de interesse, verificou-se, entre as proposições a elas apensadas, a existência de projetos afins que porventura não tivessem retornado a partir das buscas nas bases de dados.

Os resultados foram apresentados de forma narrativa, descrevendo-se o conteúdo dos projetos e a situação atual de sua tramitação. $\mathrm{O}$ resumo dos procedimentos legislativos e a descrição do processo decisório até o momento basearam-se nas fichas de tramitação, publicizadas nas páginas da Câmara dos Deputados e do Senado Federal na Internet. 


\section{Resultados}

Ao todo, foram identificadas 11 propostas legislativas que eram endereçadas à tributação de bebidas açucaradas, cujas principais características são apresentadas no Quadro 1. Dessas, sete eram projetos de Lei Ordinária (sob a sigla PLS quando eram apresentados no Senado Federal e sob a sigla PL quando na Câmara dos Deputados), que tinham como objetivo o aumento de imposto ou a criação de novo imposto para esse tipo de produto. Outras quatro propostas tratavam-se de projetos de Decreto Legislativo (sob a sigla PDS quando de autoria de Senadores e sob a sigla PDC quando de autoria de Deputados Federais), que visavam sustar um ato normativo do Poder Executivo Federal que alterou a alíquota do Imposto sobre Produtos Industrializados (IPI) dos concentrados de refrigerantes.

\section{Quadro 1}

Propostas legislativas relacionadas à tributação de bebidas açucaradas em tramitação no Congresso Nacional brasileiro na primeira metade da Década da Ação em Nutrição (2016-2020).

\section{PLS no 430/2016}

Autor: Senador Jorge Viana (PT-AC)

Data de apresentação: 23 de novembro de 2016

Ementa: Institui Contribuição de Intervenção no Domínio Econômico incidente sobre a comercialização da produção e da importação de refrigerantes e bebidas açucarados (Cide-Refrigerantes) e dá outras providências.

Situação da tramitação: arquivada

Ficha de tramitação: https://www25.senado.leg.br/web/atividade/materias/-/materia/127624

PL no 8.541/2017

Autor: Deputado Paulo Teixeira (PT-SP)

Data de apresentação: 12 de setembro de 2017

Ementa: Aumenta a alíquota do Imposto sobre Produtos Industrializados incidente sobre a importação ou saída de bebidas não alcoólicas adoçadas com açúcar.

Situação da tramitação: em tramitação

Ficha de tramitação: https://www.camara.leg.br/proposicoesWeb/fichadetramitacao?idProposicao=2150996

\section{PL no 8.675/2017}

Autor: Deputado Sérgio Vidigal (PDT-ES)

Data de apresentação: 21 de setembro de 2017

Ementa: Institui a Contribuição de Intervenção no Domínio Econômico sobre a comercialização de bebidas processadas adicionadas de açúcar Situação da tramitação: em tramitação

Ficha de tramitação: https://www.camara.leg.br/proposicoesWeb/fichadetramitacao?idProposicao=2152715

\section{PL no 10.075/2018}

Autor: Deputado Áureo Ribeiro (SD-RJ)

Data de apresentação: 18 de abril de 2018

Ementa: Acrescenta os §§ 6o e 7o ao art. 15 da Lei no 13.097, de 19 de janeiro de 2015, a fim de elevar a alíquota do Imposto sobre Produtos Industrializados incidente sobre bebidas não alcoólicas adoçadas com açúcar. (Redução do consumo de açúcar.)

Situação da tramitação: em tramitação

Ficha de tramitação: https://www.camara.leg.br/proposicoesWeb/fichadetramitacao?idProposicao=2172611

\section{PDS no 57/2018}

Autores: Senadora Vanessa Grazziotin (PCdoB-AM) e Senador Omar Aziz (PSD-AM)

Data de apresentação: 4 de junho de 2018

Ementa: Susta o Decreto no 9.394, de 30 de maio de 2018, que altera a Tabela de Incidência do Imposto sobre Produtos Industrializados -

TIPI, aprovada pelo Decreto no 8.950, de 29 de dezembro de 2016.

Situação da tramitação: rejeitada

Ficha de tramitação: https://www25.senado.leg.br/web/atividade/materias/-/materia/133495 
Quadro 1 (continuação)

\section{PDS no 59/2018}

Autor: Senador Eduardo Braga (MDB-AM)

Data de apresentação: 5 de junho de 2018

Ementa: Susta o Decreto no 9.394, de 30 de maio de 2018, que altera a Tabela de Incidência do Imposto sobre Produtos Industrializados -

TIPI, aprovada pelo Decreto no 8.950, de 29 de dezembro de 2016.

Situação da tramitação: rejeitada

Ficha de tramitação: https://www25.senado.leg.br/web/atividade/materias/-/materia/133518

PDC no 966/2018

Autor: Deputado Pauderney Avelino (DEM-AM)

Data de apresentação: 7 de junho de 2018

Ementa: Susta o Decreto no 9.394, de 30 de maio de 2018, que altera a Tabela de Incidência do Imposto sobre Produtos Industrializados -

TIPI, aprovada pelo Decreto no 8.950, de 29 de dezembro de 2016.

Situação da tramitação: rejeitada

Ficha de tramitação: https://www.camara.leg.br/proposicoesWeb/fichadetramitacao?idProposicao=2178236

\section{PDC no 969/2018}

Autor: Deputado Silas Câmara (PSD-AM)

Data de apresentação: 7 de junho de 2018

Ementa: Susta o Decreto no-9.394, de 30 de maio de 2018, que altera a Tabela de Incidência do Imposto sobre Produtos Industrializados -

TIPI, aprovada pelo Decreto no 8.950, de 29 de dezembro de 2016.

Situação da tramitação: rejeitada

Ficha de tramitação: https://www.camara.leg.br/proposicoesWeb/fichadetramitacao?idProposicao=2178370

PL no 250/2019

Autor: Deputado Assis Carvalho (PT-PI)

Data de apresentação: 4 de fevereiro de 2019

Ementa: Institui a Contribuição de Intervenção no Domínio Econômico sobre a comercialização de bebidas processadas adicionadas de açúcar Situação da tramitação: em tramitação

Ficha de tramitação: https://www.camara.leg.br/proposicoesWeb/fichadetramitacao?idProposicao=2152715

PLS no 2.183/2019

Autor: Senador Rogério Carvalho (PT-SE)

Data de apresentação: 9 de abril de 2019

Ementa: Institui Contribuição de Intervenção no Domínio Econômico incidente sobre a comercialização da produção e da importação de refrigerantes e bebidas açucarados (Cide-Refrigerantes) e dá outras providências.

Situação da tramitação: em tramitação

Ficha de tramitação: https://www25.senado.leg.br/web/atividade/materias/-/materia/136266

PL no 3.320/2019

Autor: Deputado Felipe Carreras (PSB-ES)

Data de apresentação: 4 de junho de 2019

Ementa: Institui Contribuição de Intervenção no Domínio Econômico incidente sobre alimentos industrializados e reduz a zero as alíquotas da Contribuição para o PIS/Pasep e da Cofins incidentes na importação e na comercialização de alimentos orgânicos destinados ao consumo humano.

Situação da tramitação: em tramitação

Ficha de tramitação: https://www.camara.leg.br/proposicoesWeb/fichadetramitacao?idProposicao=2206540

PDC: projeto de Decreto Legislativo de autoria de Deputados Federais; PDS: projeto de Decreto Legislativo de autoria de Senadores; PL: projeto de Lei Ordinária apresentado na Câmara dos Deputados; PLS: projeto de Lei Ordinária apresentado no Senado Federal. 
A seguir, são descritos o processo decisório das propostas identificadas, agrupadas de acordo com seu apensamento, e a situação atual de sua tramitação. Na Figura 1, situa-se a tramitação das proposições ao longo da Década da Ação em Nutrição.

O PLS no 430/2016, apresentado pelo Senador Jorge Viana (PT-AC), foi a primeira iniciativa legislativa a tramitar no Congresso Nacional atendendo à recomendação da OMS e da OPAS em aumentar o preço das bebidas açucaradas como medida de saúde pública para o controle da obesidade. Institui a Contribuição de Intervenção no Domínio Econômico (Cide) sobre a comercialização da produção e da importação de refrigerantes e bebidas açucaradas, a qual é denominada de Cide-Refrigerantes. Por não especificar os tipos de bebidas açucaradas aos quais o imposto se aplicaria ou estabelecer critérios relativos às quantidades de açúcar adicionado, apenas excluindo a aplicação às bebidas alcoólicas, o projeto apresenta um escopo ampliado. Propõe ainda a destinação dos recursos arrecadados para o Fundo Nacional de Saúde (FNS), sem delimitar de que forma deverão ser empregados, conferindo autonomia aos gestores do Sistema Único de Saúde (SUS). Foi designado para tramitar apenas pela Comissão de Assuntos Econômicos (CAE), em decisão terminativa. Não recebeu emendas e foi distribuído para o relator, o Senador Ricardo Ferraço (PSDB-ES), o qual não se manifestou até dezembro de 2018. Foi então arquivado ao fim da 55a Legislatura (2015-2019).

O PL no 8.541/2017 e seus apensados (PL no 8.675/2017, PL no 10.075/2018 e PL no 250/2019) estão sujeitos à apreciação conclusiva pelas seguintes comissões: Comissão de Seguridade Social e Família (CSSF), Comissão de Desenvolvimento Econômico, Indústria, Comércio e Serviços (CDEICS), Comissão de Finanças e Tributação (CFT) e Comissão de Constituição e Justiça e de Cidadania (CCJC).

O mais antigo deles, PL no 8.541/2017, de autoria do Deputado Paulo Teixeira (PT-SP), é o primeiro projeto de lei a tramitar na Câmara dos Deputados com o objetivo de aumentar a tributação sobre as bebidas açucaradas para combater a obesidade. Propõe alterações na Lei no 13.097, de 2015, para aumentar o IPI incidente sobre as bebidas não alcoólicas adicionadas de açúcar, estabelecendo, em

\section{Figura 1}

Tramitação das proposições legislativas relacionadas à tributação de bebidas açucaradas no Congresso Nacional brasileiro ao longo da Década da Ação em Nutrição (2016-2020).

\section{Década da Ação em Nutrição}

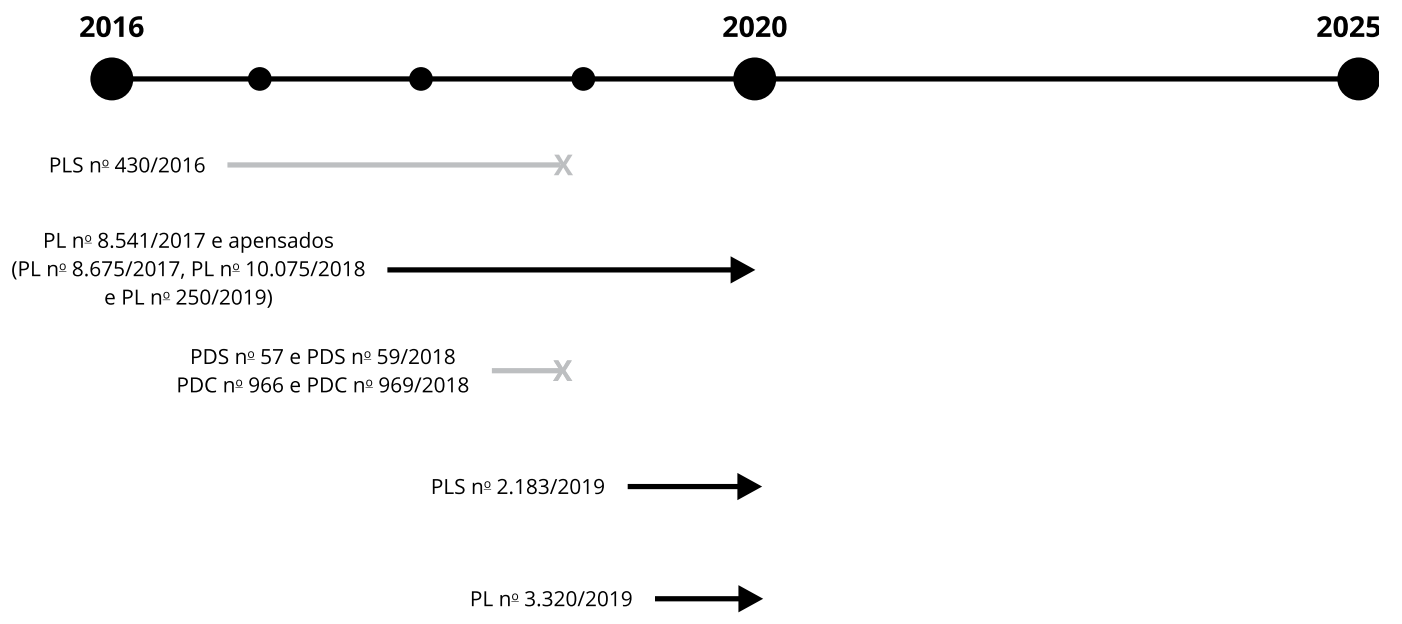

PDC: projeto de Decreto Legislativo de autoria de Deputados Federais; PDS: projeto de Decreto Legislativo de autoria de Senadores; PL: projeto de Lei Ordinária apresentado na Câmara dos Deputados; PLS: projeto de Lei Ordinária apresentado no Senado Federal. 
5\%, a alíquota incidente sobre o valor do produto no desembaraço aduaneiro e na saída dos estabelecimentos industriais ou equiparados e aumento em 25\% nos valores de IPI, PIS/Pasep (Programa de Integração Social/Programa de Formação do Patrimônio do Servidor Público), Cofins (Contribuição para o Financiamento da Seguridade Social), PIS/Pasep-Importação e Cofins-Importação para esses produtos.

Também em linha com a recomendação da OMS e da OPAS, o Deputado Sérgio Vidigal (PDT-ES) apresentou o $P L$ no 8.675/2017 que propõe a criação da Cide sobre a importação e comercialização de bebidas não alcoólicas adicionadas de açúcar. Estabelecem-se alíquotas diferenciadas e progressivas, dependendo da quantidade de açúcar adicionado e veda-se a concessão de qualquer tipo de isenção tributária a esses produtos. Determina que os recursos arrecadados por meio do imposto deverão ser repassados ao FNS para que sejam, preferencialmente, empregados em programas e ações de prevenção e combate à obesidade, em especial à infantil.

Em 2018, foi apresentado o PL no 10.075/2018, de autoria de Deputado Áureo Ribeiro (SD-RJ). Com uma proposta semelhante à do projeto do Deputado Paulo Teixeira (PT-SP), estabelece mudanças na Lei no 13.097, de 2015, para aumentar o IPI sobre bebidas não alcoólicas adoçadas com açúcar, porém com tributação mais severa (estabelece o dobro da alíquota para bebidas com conteúdo de açúcar superior a $5 \mathrm{~g}$ por $100 \mathrm{~mL}$ e o triplo para produtos com conteúdo superior a $10 \mathrm{~g}$ de açúcar por $100 \mathrm{~mL}$ ) e estende a cobrança do imposto para néctares de frutas e repositores hidroeletrolíticos. Além disso, proíbe que seja concedida qualquer isenção ou redução de IPI para bebidas não alcoólicas adoçadas com açúcar.

No ano seguinte, o Deputado Assis Carvalho (PT-PI) apresentou o PL no 250/2019. Nele, propõe que as alíquotas de PIS/Pasep, Cofins, PIS/Pasep-Importação e Cofins-Importação de bebidas adicionadas de açúcar, edulcorantes e aromatizantes sejam aumentadas em $1 / 3$, no caso de produtos que tenham até $15 \mathrm{~g}$ de açúcar adicionado em cada $240 \mathrm{~mL}$, e em $2 / 3$, para aqueles que contenham mais de $15 \mathrm{~g}$ por $240 \mathrm{~mL}$. Estabelece ainda que os valores de IPI desses produtos não devem ser inferiores a $10 \%$ e $18 \%$, respectivamente. A tributação proposta não se aplica, contudo, a bebidas à base de soja ou de leite e cacau, néctares de frutas e àquelas destinadas a praticantes de atividade física.

Em 2018, durante a tramitação pela CSSF, os PL no 8.541/2017, PL no 8.675/2017 e PL no 10.075/2018 receberam parecer favorável à aprovação, na forma de um projeto de lei substitutivo apresentado pelo Deputado Jorge Silva (SD-ES). Esse substitutivo abarca as principais recomendações dos projetos, propondo tanto o aumento do IPI quanto a criação da Cide sobre as bebidas não alcoólicas industrializadas adicionadas de açúcar, com alíquotas escalonadas a depender do teor de açúcar adicionado e previsão de que os recursos arrecadados sejam direcionados ao FNS.

O relatório com o substitutivo não chegou a ser apreciado, tendo sido solicitada a retirada de pauta pelos Deputados Marcus Pestana (PSDB-MG) e Darcísio Perondi (MDB-RS) e requerida audiência pública pelo Deputado Arnaldo Faria de Sá (PP-SP), realizada em dezembro de 2018. As proposições foram arquivadas com o fim da 55a Legislatura (2015-2019), sendo desarquivadas em fevereiro de 2019, por requerimento do Deputado Paulo Teixeira (PT-SP), e então apensado o PL no 250/2019. A última movimentação da matéria foi em abril de 2019, quando se designou relator o Deputado Darcísio Perondi (MDB-RS), que não se encontra em exercício do cargo atualmente.

Iniciativa do Senador Rogério Carvalho (PT-SE), o PLS no 2.183/2019 é, na verdade, o mesmo projeto que havia sido apresentado pelo Senador Jorge Viana (PT-AC) em 2016 e que foi arquivado ao fim da 55a Legislatura (2015-2019) sem ter sido apreciado. Atualmente, encontra-se em tramitação na Comissão de Assuntos Sociais (CAS) do Senado Federal, entre cujas atribuições está a análise de mérito de proposições legislativas relativas à área da saúde. Em 5 de junho de 2019, já contava com um relatório favorável à sua aprovação, do Senador Romário (Podemos-RJ), e pela rejeição da emenda aditiva proposta pelo Senador Luís Carlos Heinze (PP-RS), que propunha a repartição dos recursos arrecadados a partir da instituição do imposto com estados e municípios, estando pronto para apreciação na Comissão. Na ocasião, solicitou-se vista coletiva da proposição após o Senador Marcelo Castro (MDB-PI) apontar que sua aprovação impactaria a Zona Franca de Manaus (ZFM), e o Senador Otto Alencar (PSD-BA) requereu, junto ao Plenário do Senado Federal, que o Ministro de Estado da Economia se manifestasse a respeito da criação desse novo imposto. Em outubro de 2019, o projeto foi redistribuído, sendo o Senador Mecias de Jesus (Republicanos-RR) designado o novo relator. Até o momento, não foram recebidos a manifestação do Ministro de Estado da Economia ou o novo relatório. 
Apresentado pelo Deputado Felipe Carreras (PSB-ES), o PL no 3.320/2019 apresenta um escopo um pouco mais amplo: com o objetivo de incentivar a produção e o consumo de alimentos orgânicos, propõe a extinção das alíquotas de contribuição do PIS/Pasep e da Cofins incidentes na importação e comercialização desses produtos e, como medida de compensação, a criação da Cide sobre a importação e a fabricação de alimentos industrializados para consumo humano. Embora o projeto estabeleça a cobrança da Cide sobre produtos ultraprocessados em geral, determinando inclusive limites relacionados aos teores de açúcares adicionados, gorduras saturadas e trans e sódio, tem aplicação limitada sobre as bebidas açucaradas, posto que exclui do rol bebidas à base de soja ou leite com cacau, néctares de frutas, repositores hidroeletrolíticos, sucos de frutas com conteúdo de frutas ou vegetais superior a $50 \%$ de sua composição e alimentos para atletas. Por sua natureza um pouco distinta dos projetos anteriores, pois pauta como objetivo principal estimular a produção e o consumo de alimentos orgânicos, o $P L$ no 3.320/2019 tramita apensado ao $P L$ no 7.372/2017, de autoria do Deputado Veneziano Vital do Rêgo (MDB-PB), que institui incentivos fiscais para operações com produtos sem lactose e produtos orgânicos. Sujeito à apreciação conclusiva pela CDEICS e pela CFT, o PL no 3.320/2019 foi rejeitado na CDEICS e aguarda, desde dezembro de 2019, o início dos procedimentos legislativos na CFT.

O PDS no 57/2018 e o PDS no 59/2018, de autoria da Senadora Vanessa Grazziotin (PCdoB-AM) e do Senador Eduardo Braga (MDB-AM), respectivamente, assim como o PDC no 966/2018 e o PDC no 969/2018, de autoria do Deputado Pauderney Avelino (DEM-AM) e do Deputado Silas Câmara (PSD-AM), respectivamente, tratavam-se de projetos de Decreto Legislativo que tinham como objetivo sustar os efeitos do Decreto no 9.394, de 30 de maio de 2018. Esse Decreto, editado pelo então Presidente Michel Temer, reduziu o valor do IPI dos concentrados de refrigerantes de 20\% para $4 \%$. O PDS no 57/2018 foi rapidamente aprovado no Senado Federal, após tramitar pela Comissão de Constituição de Justiça e pelo Plenário, e enviado para apreciação na Câmara dos Deputados, que atuou como casa revisora da matéria. Lá, foi renumerado como PDC no 1.011/2018, e a ele foram apensados o PDC no 966/2018 e o PDC no 969/2018. Apreciados na CFT, com decisão terminativa, foram rejeitados e arquivados ao fim da 55a Legislatura (2015-2019).

\section{Discussão}

Passados cinco anos do início da Década da Ação em Nutrição, o excesso de peso e a obesidade continuam aumentando na população brasileira. Em 2019, segundo dados da Pesquisa Nacional de Saúde, entre os adolescentes entre 15 e 17 anos de idade, 19,4\% tinham excesso de peso, e 6,7\%, obesidade, enquanto, entre a população adulta, o excesso de peso atingia 60,3\%, e a obesidade, $25,9 \% 14$.

Durante esse período, tramitaram, no Congresso Nacional brasileiro, sete projetos de Lei Ordinária com o objetivo de aumentar a tributação sobre bebidas açucaradas, dos quais seis permanecem em apreciação. Apesar de a medida não figurar entre os objetivos relativos à Década da Ação em Nutrição pactuados pelo Ministério da Saúde, isso mostra haver interesse por parte de um grupo de parlamentares em implementar essa política fiscal recomendada pela OMS e pela OPAS.

De modo geral, as propostas em andamento preconizam o aumento das alíquotas de impostos já existentes, tais como o IPI, PIS/Pasep e Cofins ou a criação de um novo tributo exclusivo para esse tipo de produto. Ressalta-se uma limitação dos projetos que estabelecem a majoração da tributação das bebidas açucaradas a partir de um aumento percentual calculado sobre a alíquota vigente do IPI. Uma vez que a tabela desse imposto é fixada por meio de Decreto do Poder Executivo Federal, pode ser facilmente alterada por iniciativa da Presidência da República e sem necessidade de tramitação pelo Congresso Nacional. Assim, uma medida como essa somente seria efetiva se houver o comprometimento do Poder Executivo em não reduzir os valores de IPI para compensar a sobretaxação.

Nota-se que ainda falta consenso em relação a sobre quais bebidas açucaradas a tributação deveria incidir. A tributação escalonada de acordo com o teor de açúcar presente nas bebidas, proposta em alguns dos projetos identificados, poderia contribuir para que os consumidores optassem por versões com menor quantidade de açúcar adicionado 9,10,11. Outra possível consequência seria o estímulo à reformulação dos produtos pela indústria de ultraprocessados, mas ainda não há evidências científicas dos países que já adotaram esse tipo de tributação de que isso realmente 
aconteça. Destaca-se também a preocupação, expressa em algumas das propostas, em destinar os valores arrecadados ao SUS, cujo financiamento é insuficiente e conta com reduzida participação de recursos fiscais 15 .

Independentemente de qual estratégia venha a ser utilizada para o aumento da tributação das bebidas açucaradas, uma vez adotada essa política no Brasil, espera-se que promova uma redução no consumo desse tipo de produto, assim como ocorreu em outros países que adotaram a medida 9,10,11. Acredita-se também que, do ponto de vista da saúde populacional, poderá ter algum impacto - ainda que limitado - sobre a escalada do sobrepeso e da obesidade. Isso porque, no país, principalmente entre a população menos favorecida do ponto de vista socioeconômico, há uma associação inversa entre o preço dos produtos ultraprocessados em geral e a prevalência de sobrepeso e obesidade. A partir de dados da POF de 2008-2009, estimou-se que cada aumento na ordem de 1\% nos preços desses produtos poderia levar a uma redução de 0,33\% e 0,59\%, respectivamente, nas prevalências de sobrepeso e de obesidade 16.

No período de interesse deste estudo, tramitaram ainda quatro projetos de Decreto Legislativo, uma prerrogativa constitucional do Congresso Nacional para sustar os atos normativos infralegais da Presidência da República que se entenda que exorbitem de seu poder regulamentar 12. Essas propostas visavam anular os efeitos do Decreto no 9.394, de 30 de maio de 2018 17, editado como uma das medidas de ajuste fiscal para compensar a perda de arrecadação gerada após o compromisso do Governo Federal em reduzir em $\mathrm{R} \$$ 0,46 o preço do litro do diesel, atendendo à reivindicação dos caminhoneiros que paralisaram o país naquele mês. Ao reduzir o IPI dos concentrados de refrigerantes de $20 \%$ para $4 \%$, o ato teve como efeito secundário o aumento da tributação sobre concentrados de refrigerantes produzidos na ZFM, principal polo nacional do setor. Isso ocorre porque as empresas lá instaladas - dentre elas as multinacionais Coca-Cola e Ambev, que detêm 80\% do mercado nacional de refrigerantes - são favorecidas por uma manobra fiscal há anos questionada pela Receita Federal. Apesar de isentas do pagamento do IPI por estarem estabelecidas na ZFM, recebem créditos tributários equivalentes ao valor que teoricamente seria pago por esse imposto. O governo acaba então subsidiando a fabricação de concentrados de refrigerantes. Cria-se também um contrassenso: para essas empresas, quanto maior o valor cobrado pelo imposto melhor, pois isso gera um volume maior de créditos tributários 18,19,20. Assim, se aprovados, os Decretos Legislativos restabeleceriam uma alíquota mais favorável ao setor, indo na contramão do que é preconizado como uma medida efetiva para a redução do consumo de bebidas açucaradas e o combate à obesidade e às doenças crônicas não transmissíveis associadas à má alimentação. Embora a matéria tenha logrado êxito no Senado Federal, felizmente foi rejeitada e arquivada na Câmara dos Deputados. Essa tramitação trata-se de um caso emblemático e complexo, que está sendo objeto de análises acadêmicas em maior profundidade.

Diante da situação atual da tramitação das iniciativas legislativas, pode-se afirmar que ainda há um longo caminho a ser percorrido para o aumento da tributação das bebidas açucaradas no país. O processo legislativo no Congresso Nacional é complexo, moroso e está sujeito à intensa atuação de grupos de interesse economicamente poderosos que buscam influenciar a tomada de decisão. As indústrias de açúcar e de bebidas açucaradas têm um importante histórico de contribuições financeiras para as campanhas eleitorais de candidatos ao Poder Legislativo Federal, fazem lobby junto aos parlamentares, e suas associações se posicionam abertamente contra essa política fiscal 21,22. Assim, sua aprovação depende não apenas do comprometimento dos parlamentares com a saúde pública, mas também da ausência de conflitos de interesse e da sua capacidade de não ceder às pressões do setor industrial. A tudo isso, soma-se o fato de que, durante a pandemia de COVID-19, as reuniões deliberativas das Comissões de mérito nas quais atualmente tramitam os projetos de Lei Ordinária - CFT e CSSF, na Câmara dos Deputados, e CAS, no Senado Federal - encontram-se paralisadas. Esse panorama impõe dois grandes riscos: que nenhum dos projetos sejam convertidos em lei até 2025 ou, caso o sejam, que não tenham tempo hábil para causar qualquer impacto do ponto de vista da saúde pública ainda dentro da Década da Ação em Nutrição. 


\section{Colaboradores}

A. B. Mariath contribuiu com a concepção do estudo e redação e revisão crítica do manuscrito. A. P. B. Martins contribuiu com a concepção do estudo e revisão crítica do manuscrito.

\section{Informações adicionais}

ORCID: Aline Brandão Mariath (0000-0003-46946486); Ana Paula Bortoletto Martins (0000-00033560-4472).

\section{Agradecimentos}

Agradecemos a Gabriel Siqueira Ortiz Dias, do Serviço de Pesquisas Legislativas (Sepel) do Senado Federal, e Ana Paula Oliveira Teles Deusdará, da Seção de Indexação de Matérias Legislativas da Câmara dos Deputados, por gentilmente auxiliarem nas buscas nas bases internas de dados.

\section{Referências}

1. Instituto Brasileiro de Geografia e Estatística. Pesquisa de Orçamentos Familiares 2008-2009. Antropometria e estado nutricional de crianças, adolescentes e adultos no Brasil. https:// biblioteca.ibge.gov.br/visualizacao/livros/ liv45419.pdf (acessado 19/Fev/2020).

2. World Health Organization. Brazil first country to make specific commitments in UN Decade of Action on Nutrition. https://www. who.int/nutrition/decade-of-action/brazilcommitment-22may2017/en/ (acessado em 12/Nov/2020).

3. Organización Panamericana de la Salud. Experiencia de México en el estabelecimiento de impuestos a las bebidas azucaradas como estrategia de salud pública. https://iris. paho.org/bitstream/handle/10665.2/18390/ 978-92-75-31871-3_es (acessado em 25/Fev/ 2020).

4. World Health Organization. Report of the Commission on Ending Childhood Obesity. https://www.who.int/end-childhood-obesity/ publications/echo-report/en/ (acessado em 12/Mar/2020).

5. World Health Organization. Taxes on sugary drinks: why do it? https://apps.who.int/ iris/bitstream/handle/10665/260253/WHONMH-PND-16.5Rev.1-eng.pdf;jsessionid= B3313C543AC2E1927B2250A7E657F134?se quence $=1$ (acessado em 12/Mar/2020).

6. Waterlander WE, Ni Mhurchu C, Steenhuis IH. Effects of a price increase on purchases of sugar sweetened beverages. Results from a randomized controlled trial. Appetite 2014; 78:32-9.

7. Acton RB, Hammond D. The impact of price and nutrition labelling on sugary drink purchases: results from an experimental marketplace study. Appetite 2018; 121:129-37.

8. Acton RB, Jones AC, Kirkpatrick SI, Roberto CA, Hammond D. Taxes and front-of-package labels improve the healthiness of beverage and snack purchases: a randomized experimental marketplace. Int J Behav Nutr Phys Act 2019; $16: 46$.

9. Nakamura R, Mirelman AJ, Cuadrado C, Silva-Illanes N, Dunstan J, Suhrcke M. Evaluating the 2014 sugar-sweetened beverage tax in Chile: an observational study in urban areas. PLoS Med 2018; 15:e1002596.

10. Alvarado M, Unwin N, Sharp SJ, Hambleton I, Murphy MM, Samuels TA, et al. Assessing the impact of the Barbados sugar-sweetened beverage tax on beverage sales: an observational study. Int J Behav Nutr Phys Act 2019; 16:13.

11. Pedraza LS, Popkin BM, Batis C, Adair L, Robinson WR, Guilkey DK, et al. The caloric and sugar content of beverages purchased at different store-types changed after the sugary drinks taxation in Mexico. Int J Behav Nutr Phys Act 2019; 16:103. 
12. Brasil. Constituição da República Federativa do Brasil de 1988. http://www.planalto.gov. br/ccivil_03/Constituicao/Constituicao.htm (acessado em 21/Abr/2020).

13. Mariath AB, Martins APB. Ultra-processed food industry regulation for tackling obesity and diet-related non-communicable diseases in the Brazilian legislature: many proposals, no enactments. Public Health Nutr 2021; 24:3110-5.

14. Instituto Brasileiro de Geografia e Estatística. Pesquisa Nacional de Saúde 2019: atenção primária à saúde e informações antropométricas. Rio de Janeiro: Instituto Brasileiro de Geografia e Estatística; 2020.

15. Mendes A, Funcia FR. O SUS e seu financiamento. In: Marques RM, Piola SF, Roa AC, organizadores. Sistema de saúde no Brasil: organização e financiamento. Rio de Janeiro: Associação Brasileira de Economia da Saúde; 2016. p. 139-68.

16. Passos CM, Maia EG, Levy RB, Martins APB, Claro RM. Association between the price of ultra-processed foods and obesity in Brazil. Nutr Metab Cardiovasc Dis 2020; 30:589-98.

17. Brasil. Decreto no 9.394, de 30 de maio de 2018. Altera a Tabela de Incidência do Imposto sobre Produtos Industrializados - TIPI, aprovada pelo Decreto no 8.950, de 29 de dezembro de 2016. Diário Oficial da União 2018; 30 mai.
18. Pinto LC. Isenção é de R\$ 3 bi na Zona Franca. Folha de S.Paulo 1997; 5 out. https://www1. folha.uol.com.br/fsp/1997/10/05/brasil/13. html.

19. Banco Nacional de Desenvolvimento Econômico e Social. Panoramas setoriais 2030: desafios e oportunidades para o Brasil. Rio de Janeiro: Banco Nacional de Desenvolvimento Econômico e Social; 2017.

20. Superintendência da Zona Franca de Manaus. Perfil das empresas com projetos aprovados pela SUFRAMA. http://site.suframa.gov.br/ assuntos/modelo-zona-franca-de-manaus/ PERFILABRIL2018.pdf (acessado em 10/ Mar/2020).

21. Mariath AB, Martins APB. Atuação da indústria de produtos ultraprocessados como um grupo de interesse. Rev Saúde Pública 2020; 54:107.

22. Mariath AB, Baraldi LG, Martins APB. Electoral campaign contributions: obstacle to sugary drinks regulation in the Brazilian legislature? In: Abstract book of the World Public Health Nutrition Congress. Brisbane: World Public Health Nutrition Association; 2020. p. 47. 


\section{Abstract}

Brazil was the first country to commit to the United Nations' Decade of Action on Nutrition with ambitious goals related to controlling obesity and reducing the intake of sugar-sweetened beverages. In this study, we describe legislative efforts related to sugar-sweetened beverage taxation introduced in the Brazilian Legislature throughout the first four years of this decade as well as the status of the decision-making process. We searched databases within the Chamber of Deputies and the Federal Senate for legislative proposals introduced between 2016 and 2019 that addressed sugary drinks taxation. The results are presented narratively. The content of the bills and status of the legislative process are described. Ten bills were identified. Six of them are aimed at raising taxes and are currently under consideration in the Committees by the first legislative House. Four bills had been aimed at repealing an act which increased taxes on soft drink concentrates, but they have since been rejected and archived. There still seems to be a long road ahead before taxes on sugar-sweetened beverages are raised in Brazil. The lawmaking process in the Brazilian Legislature is complex and slow. This poses two risks: no law being passed; or enacted legislation not being capable to cause significant impact on public health by 2025.

Obesity; Carbonated Beverages; Sugars; Taxes; Public Policy

\section{Resumen}

Brasil fue el primer país en comprometerse con la Década de la Acción en Nutrición de la Organización de las Naciones Unidas, con metas ambiciosas relativas al control de la obesidad y a la reducción del consumo de bebidas azucaradas. En este estudio, describimos las iniciativas legislativas relacionadas con la tributación de bebidas azucaradas, presentadas en el Congreso Nacional durante los primeros cuatro años de la Década, y la situación del proceso decisorio. Se buscaron en las bases de datos de la Cámara de los Diputados y del Senado Federal todas las propuestas presentadas entre 2016 y 2019 que tratasen el tema. Se presentan los resultados de forma narrativa, describiéndose el contenido de los proyectos y la situación de la tramitación. Se identificaron en total diez propuestas. Seis de ellas tienen como objetivo el aumento de la tributación e incluso se encuentran en apreciación de Comisiones en la Cámara de los Diputados. Cuatro propuestas buscaban demorar un acto normativo que resultó en el aumento de la tributación sobre concentrados y refrescos, que fueron rechazadas y archivadas. Todavía hay un largo camino por recorrer para el aumento de la tributación de las bebidas azucaradas en el país. La complejidad y la tardanza del proceso decisivo en el Congreso Nacional imponen dos riesgos: que ningún proyecto sea convertido en ley o, en caso de que lo sea, que no cause cualquier impacto en la salud pública hasta 2025.

Obesidad; Bebidas Gaseosas; Azúcares;

Impuestos; Política Pública
Recebido em 08/Jun/2020

Versão final reapresentada em 17/Nov/2020

Aprovado em 27/Nov/2020 
Mariath AB, Martins APB. Década da Ação em Nutrição e tributação de bebidas açucaradas no Brasil: onde estamos? Cad Saúde Pública 2021; 37(7):e00157220.

doi: 10.1590/0102-311XER157220

Onde se lê:

Aline Brandão Mariath 1,2

Ana Paula Bortoletto Martins 3

1 Departamento Médico, Câmara dos Deputados, Brasília, Brasil.

2 Faculdade de Medicina, Universidade de São Paulo, São Paulo, Brasil.

3 Núcleo de Pesquisas Epidemiológicas em Nutrição e Saúde Pública, Universidade de São Paulo, São Paulo, Brasil.

Leia-se:

Aline Brandão Mariath 1,2

Ana Paula Bortoletto Martins 3

1 Departamento Médico, Câmara dos Deputados, Brasília, Brasil.

2 Programa de Pós-graduação em Nutrição em Saúde Pública, Universidade de São Paulo, São Paulo, Brasil.

3 Núcleo de Pesquisas Epidemiológicas em Nutrição e Saúde Pública, Universidade de São Paulo, São Paulo, Brasil. 